\title{
From the River to You: USGS Real-Time Streamflow Information
}

\author{
...from the National Streamflow Information Program
}

\begin{abstract}
This Fact Sheet is one in a series that highlights information or recent research findings from the USGS National Streamflow Information Program (NSIP). The investigations and scientific results reported in this series require a nationally consistent streamgaging network with stable long-term monitoring sites and a rigorous program of data, quality assurance, management, archiving, and synthesis. NSIP produces multipurpose, unbiased surface-water information that is readily accessible to all.
\end{abstract}

\section{Introduction}

As part of the National Streamflow Information Program, the U.S. Geological Survey (USGS) operates more than 7,400 streamgages nationwide to provide streamflow information for a wide variety of uses. These uses include prediction of floods, management and allocation of water resources, design and operation of engineering structures, scientific research, operation of locks and dams, and for recreational safety and enjoyment. These streamgages are operated by the USGS in partnerships with more than 800 other Federal, State, Tribal, and local cooperating agencies. Today (2007), nearly 90 percent of streamgages record and transmit streamflow information electronically so that streamflow information is available on the World Wide Web in real time (http://waterdata. usgs.gov). Most streamgages transmit information via satellite, but a few use telephone and radio telemetry.

Collecting and delivering streamflow information from the streamgage to the World Wide Web in real time by satellite involves numerous steps and the simultaneous activities of a large array of computer hardware and software. These processes work together to ensure the prompt delivery of streamflow information to many diverse users.

\section{Collecting and Transmitting Streamflow Information}

The streamflow information collected at most streamgages is stream stage (also called gage height). This is the height of the water surface above a reference level or datum. Stream stage is measured by a variety of methods including floats, pressure transducers, and acoustic or optical sensors (fig. 1).

Stage data are measured at the time interval necessary to monitor the rise and fall of a given river, typically every 15 minutes (fig. 2). These data are stored in a data logger in the gagehouse.

On a preset schedule, typically every 1 to 4 hours, the streamgage transmits all the stage information recorded since the last transmission to a Geostationary Operational Environmental Satellite (GOES). Many streamgages have predetermined stage thresholds. When these thresholds are exceeded, the time between transmissions to the satellite will decrease from 1 to 4 hours to every 15 minutes to provide more timely data during flooding or other emergency situations.

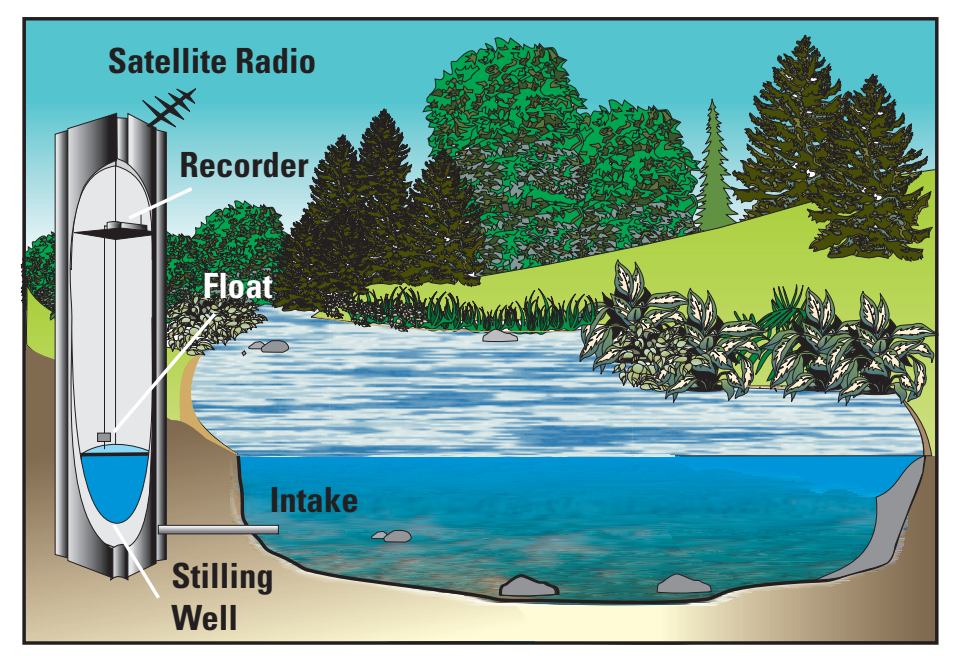

Figure 1. Stream stage is the height of the water surface above a reference level or datum. Stage can be measured by a variety of methods, including a float, as shown in this illustration. 


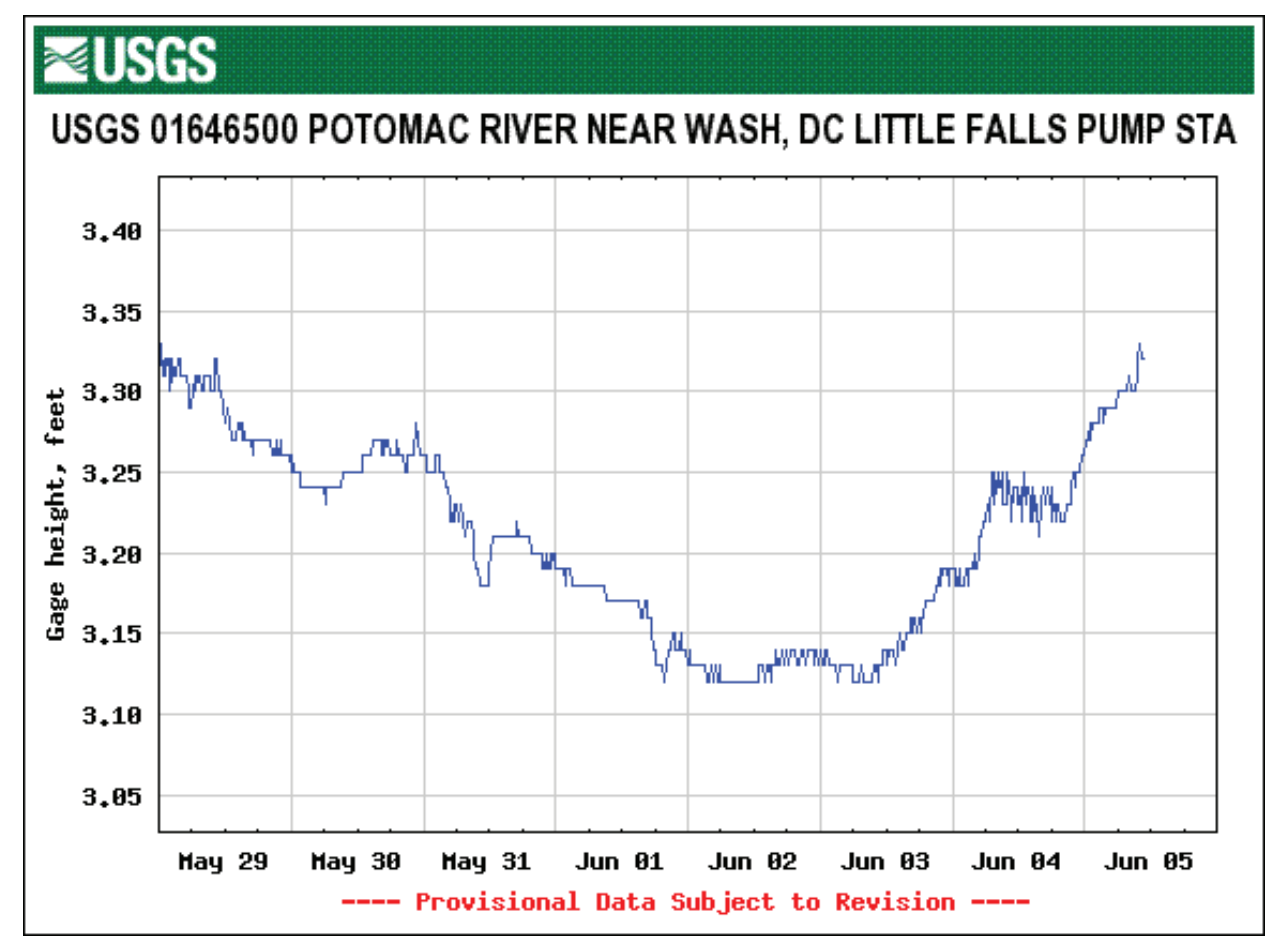

Figure 2. Fifteen-minute stage (gage height) data showing the rise and fall of the Potomac River during a 1-week period in 2007.

\section{Processing Streamflow Information}

Stream stage is an important parameter for some applications, but most users of stream information are interested in streamflow (or discharge). Because streamflow cannot currently be measured directly at the streamgage, it must be estimated from stage data. This is done using a stagedischarge rating (fig. 3). A rating is the relation between stream stage and streamflow; a rating is developed by making manual discharge measurements that cover the range of stream stage at each streamgage. Because the configuration of the stream channel at each streamgage is different, an individual rating must be developed for each streamgage. In addition, changing channel conditions require that ratings be constantly checked by making additional measurements and adjusted as appropriate (fig. 4). These checks and corrections are particularly critical during floods and droughts or other emergency situations.
Transmissions from the streamgage are sent from the GOES satellite to the National Oceanic and Atmospheric Administration's (NOAA) Command and Data Acquisition (CDA) facility at Wallops Island, Virginia. The received information is then immediately rebroadcast at much higher power to a domestic communications satellite (DOMSAT). This allows the information to be received at smaller Local Readout Ground Stations (LRGS) throughout the United States. The USGS maintains 21 LRGS systems to provide redundancy, in the event one or more systems are not operating.

Upon receipt at the LRGS, stage information is transferred almost immediately into the USGS National Water Information System (NWIS). NWIS consists of a network of more than 50 computers that collectively process all USGS water-resources data and store more than 100 years of streamflow, water-quality, and ground-water data from hundreds of thousands of sites across the country.

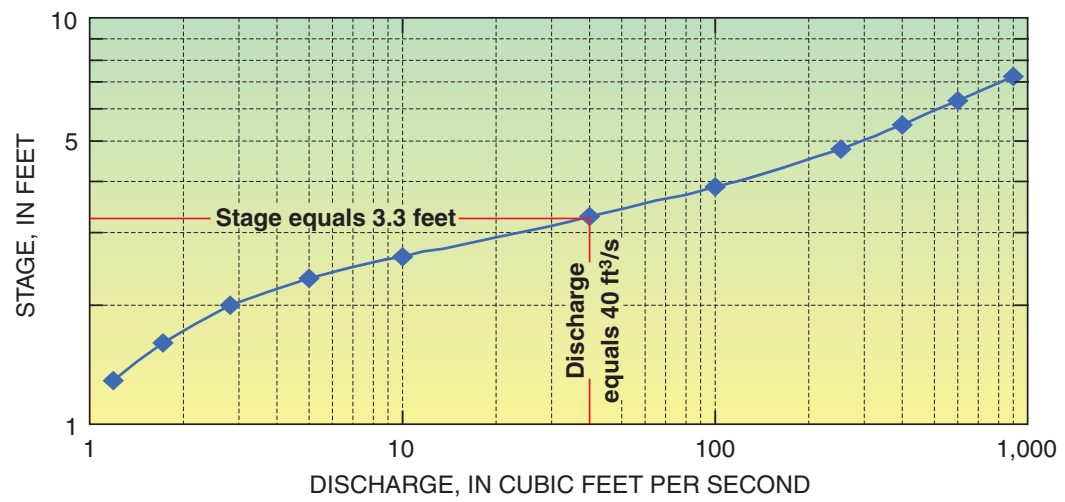

Figure 3. A rating curve relates stream stage to streamflow (discharge) through the use of manual discharge measurements. At this streamgage, a stage of 3.3 feet gives a streamflow of 40 cubic feet per second.

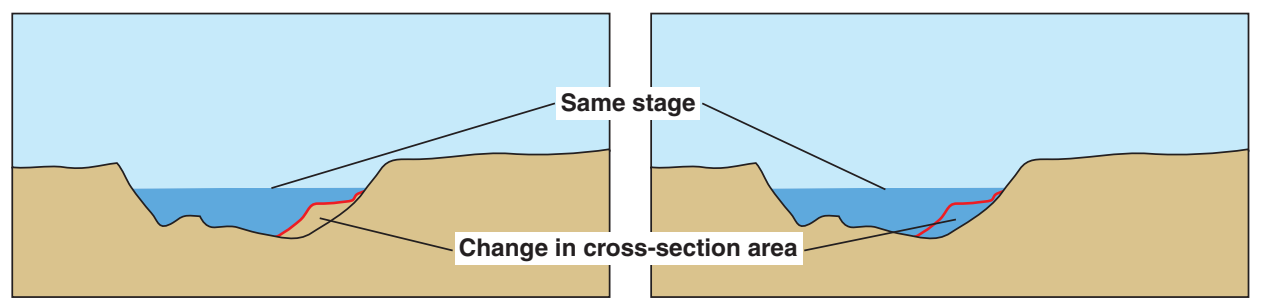

Figure 4. Because all stream channels change with time, additional manual measurements must be made to check and update the rating for each streamgage. This is particularly important during floods and droughts. 
When NWIS receives stage data from an LRGS, it uses the most recent rating developed for the streamgage to convert the stream stage to streamflow. USGS hydrographers work to ensure that the stored ratings for each streamgage match the latest discharge measurements at all times so that the computed streamflow remains as accurate as possible. Redundant NWIS systems exist across the country so that data processing can continue in the event of the failure of a local NWIS computer.

\section{Delivering Streamflow Information}

After stream stage is converted to streamflow in NWIS, the information is sent to the USGS Web site delivery system NWISWeb (http://waterdata. usgs.gov/nwis). On the NWISWeb system, current and historical stream stage and streamflow data are available in tables and graphs (fig. 5).

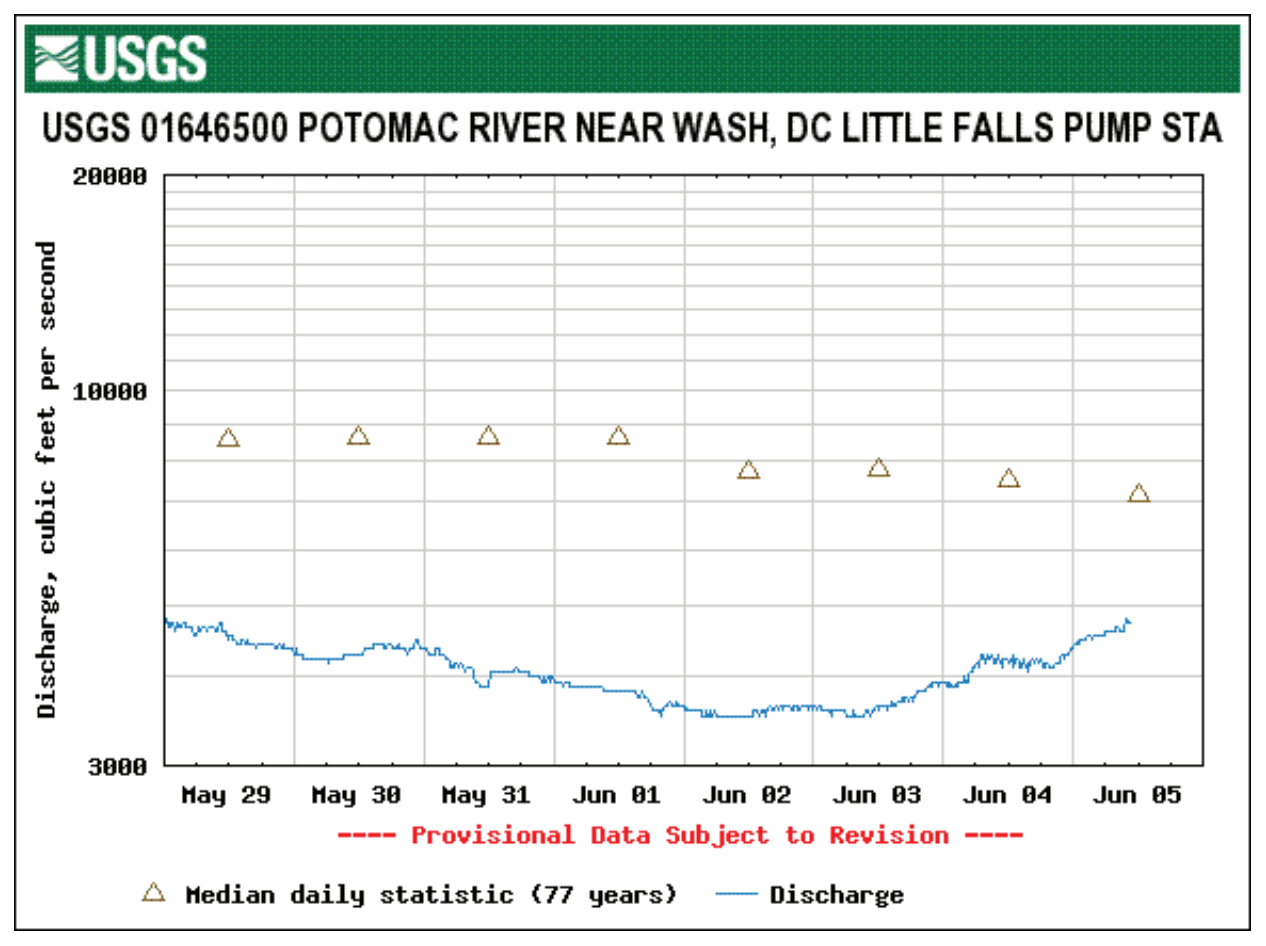

Figure 5. The streamflow (discharge) of the Potomac River in 2007 as displayed on the USGS Web site delivery system NWISWeb (http://waterdata.usgs.gov).

\section{WaterWatch -- Current water resources conditions}

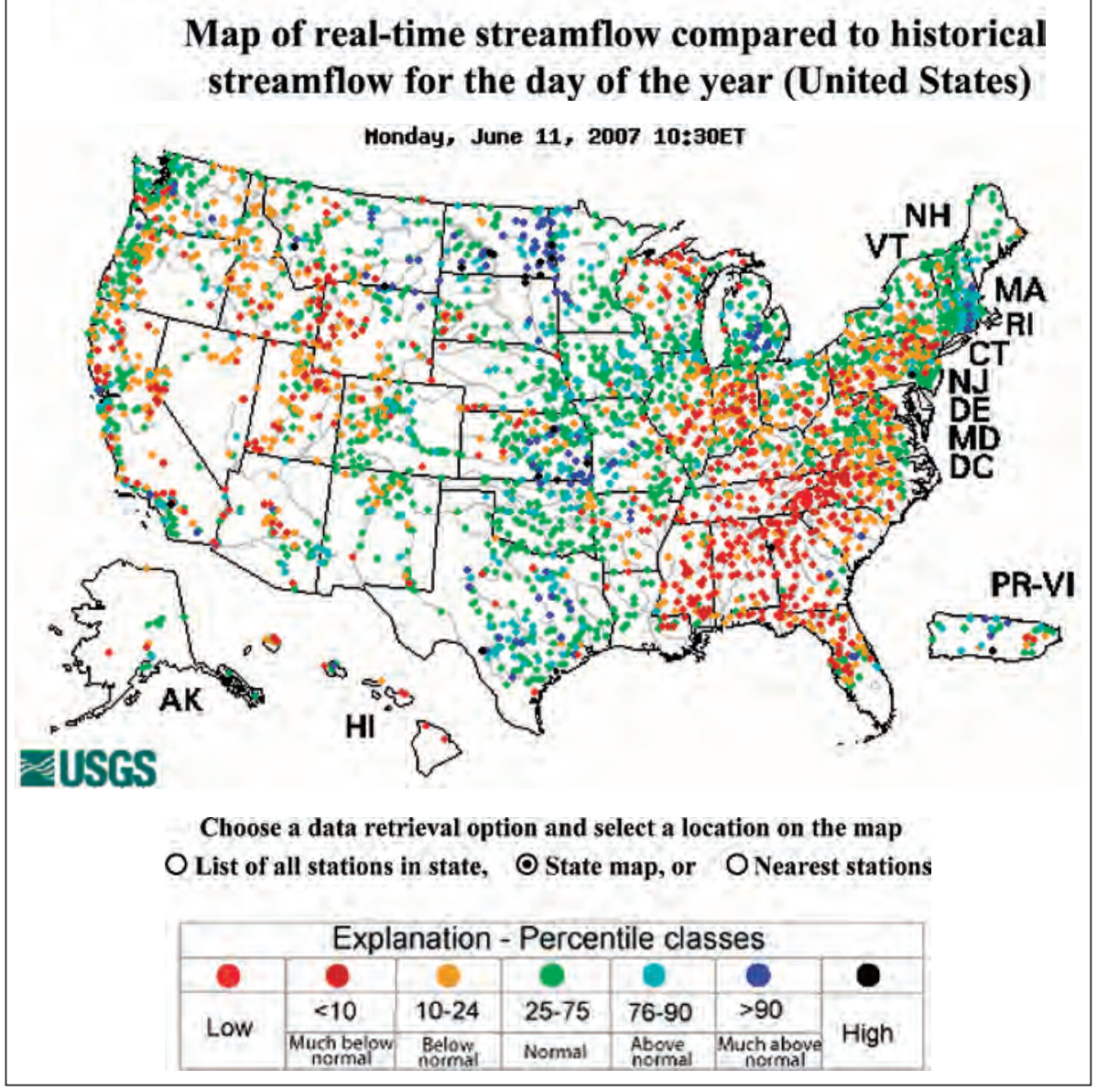

In addition, the WaterWatch Web site (fig. 6) provides maps and graphs showing real-time streamflow conditions in the United States. The "WaterWatch" Web site is at http://water.usgs.gov/waterwatch/. Maps show current streamflow as color-coded dots for about 3,000 streamgages nationwide. The colors represent percentiles of streamflow that are calculated from historical observations for the current day of the year. Only streamgages with at least 30 years of continuous record are used; this ensures that the calculated percentiles represent historical conditions.
Figure 6. The USGS WaterWatch Web site allows users to see the status of the surfacewater resources of the Nation at a glance (http://water.usgs.gov/waterwatch/). 
All systems involved in processing USGS streamflow data have redundant capabilities to minimize the potential for loss of data access. For some systems (LRGS, NWIS, NWISWeb), this redundant capability is automatic or can be brought online within a matter of minutes if there is a failure of the primary system. For other systems
(GOES, NOAA CDA, DOMSAT), several hours may be needed to switch to the backup system (fig. 7). In addition, Federal agencies with flood warning and response missions, such as the U.S. Army Corps of Engineers and the National Weather Service, maintain separate receiving capabilities to further ensure access to USGS streamflow information.
Although most streamgages have only one satellite transmitter, many critical flood-warning streamgages have redundant telemetry systems that couple satellite telemetry with radio or telephone transmissions.

By Joseph P. Nielsen and J. Michael Norris

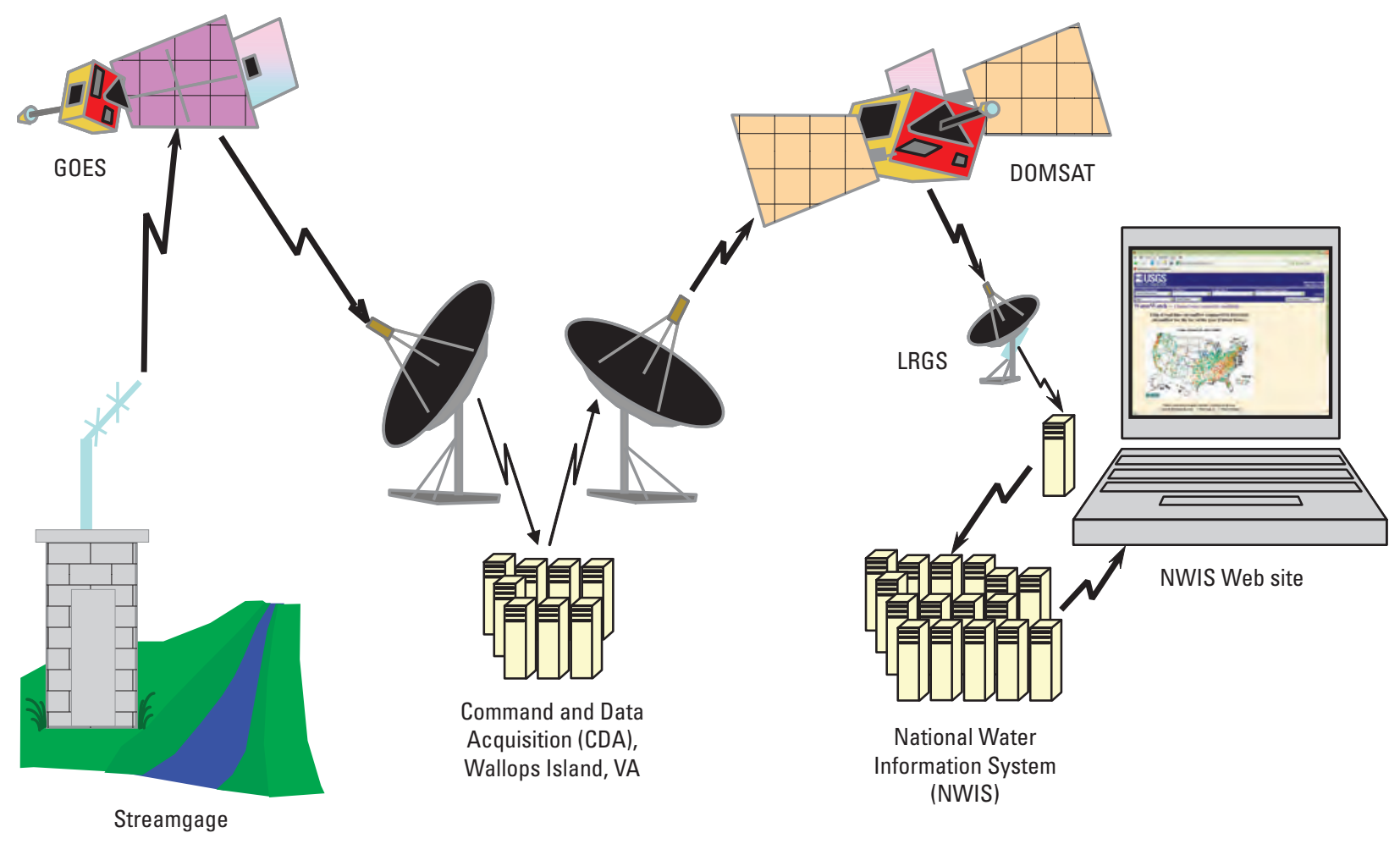

Figure 7. Streamflow information from the river to the user passes through numerous satellite and computer systems during a 10-minute period.

\section{Need Further Information?}

Water-resources programs in each State: http://water.usgs.gol

National Streamflow Information Program: http://water.usgs.gov/nsip

or contact:

J. Michael Norris

U.S. Geological Survey

361 Commerce Way

Pembroke, NH 03275

mnorris@usgs.gov

(603) 226-7847 